\title{
NOTES ON A COLLECTION OF AMBER ANTS.'
}

\section{By F. M. Carpenter.}

In a collection of parasitic hymenoptera from the Baltic Amber, now at the Bussey Institution, a number of other insects were accidently included, among which were 89 ants. This small ant collection is peculiar in that it contains a higher percentage of males than has been the case with former material. In such collections the workers have far excelled the sexual forms in respect to the number of individuals present, but in the collection before me the males are almost twice as abundant as the workers. The species represented in this material are listed below, together with a few notes on their occurrence, and the numbers identifying the specimens in the two collections (Museum of the University of Könisberg and the Fritsch collection) to which the fossils belong. The species present, except one, were described by Mayr ${ }^{2}$ in his paper, "Die Ameisen des baltischen Bersteins", and by Professor W. M. Wheeler ${ }^{3}$ in "The Ants of the Baltic Amber."

\section{Mrrmicinae}

Erebomyrma antiqua Mayr: Two males in the Univ. Königsberg collection, both without numbers. These two specimens increase the number of observed males of the species to seven.

Stenamma berendt Mayr : One male, Univ. Königsberg (xxB979). This is the third specimen of this species that has been found. It is curious that the species should be present in so small a collection as this, since only two other individuals have been seen in the 11678 amber ants that have previously been studied.

${ }^{1}$ Contribution from the Entomological Laboratory of the Bussy Institution, Harvard University, No. 274.

${ }^{2}$ Beiträge zur Naturkunde Preussens, hereausgegeben v. d. physik.-ök Ges. zu Königsbreg, 1, 1868.

${ }^{3}$ Sonderabdruck aus den Schriften der Phpsikalisch-ök. Ges. zu Königsberg, i. Pr., LV. 1914. 
Nothomyrmica rubis Mayr: One worker in the Univ. Königsberg (xxB859).

Leptothorax gracilis Mayr: One worker and one male, both in the collection of the University of Königsberg, and without numbers.

\section{Dolichoderinae}

Dolichoderus balticus Mayr: One specimen, Univ. Königsberg collection (11017/364), the sixth individual to be found.

Dolichoderus tertiarius Mayr: One male in the Univ. Königsberg collection. (137060/437).

Iridomyrmex geinitizi Mayr: Three males and three workers in the Univ. Königsberg collection (9561/289, 7501/239, xxB768, B18282, and two without numbers); one worker in the Fritsch collection (207).

Iridomyrmex gøpperti Mayr: Eight workers and one male in the Univ. Königsberg collection (B19423, xxB1771, 7444/182, and six without numbers); one worker in the Fritsch collection (186).

\section{Formicinae.}

Prenolepis henschei Mayr: One worker and one male, Univ. Königsberg collection (xxB104, 7479/217).

Prenolepis pygmcea Mayr: Nine males in the Univ. Königsberg collection $(9757 / 303,4195 / 76$, etc.); ten males in the Fritsch collection (163, 62, 96, 186, etc.).

Lasius schiefferdeckeri Mayr: Two males in the Fritsch collection $(246,229)$.

Lasius punctulatus Mayr: One female in the Fritsch collection. (230).

Formica flori Mayr: One worker and two males in the Univ. Königsberg collection (xxB908, and two without numbers); four males in the Fritsch collection $(241,216,197,138)$. 
The remaining specimens are too poorly preserved to permit satisfactory determination, and with the exception of one individual none of these presents any striking characteristics. The specimen referred to is a male ponerine (Fritsch collection, number 4) and differs from other known males of the subfamily by having a twelve-jointed antenna; a low, rounded petiole with an anteroventral keel; and forewings with the veins crowded anteriorly and basally. Professor Wheeler kindly examined this specimen, but did not regocnize it as belonging to any existing genus. However, the present knowledge of extant male ponerines is too incomplete to allow determination of the affinities of this species, until the worker has been found. 

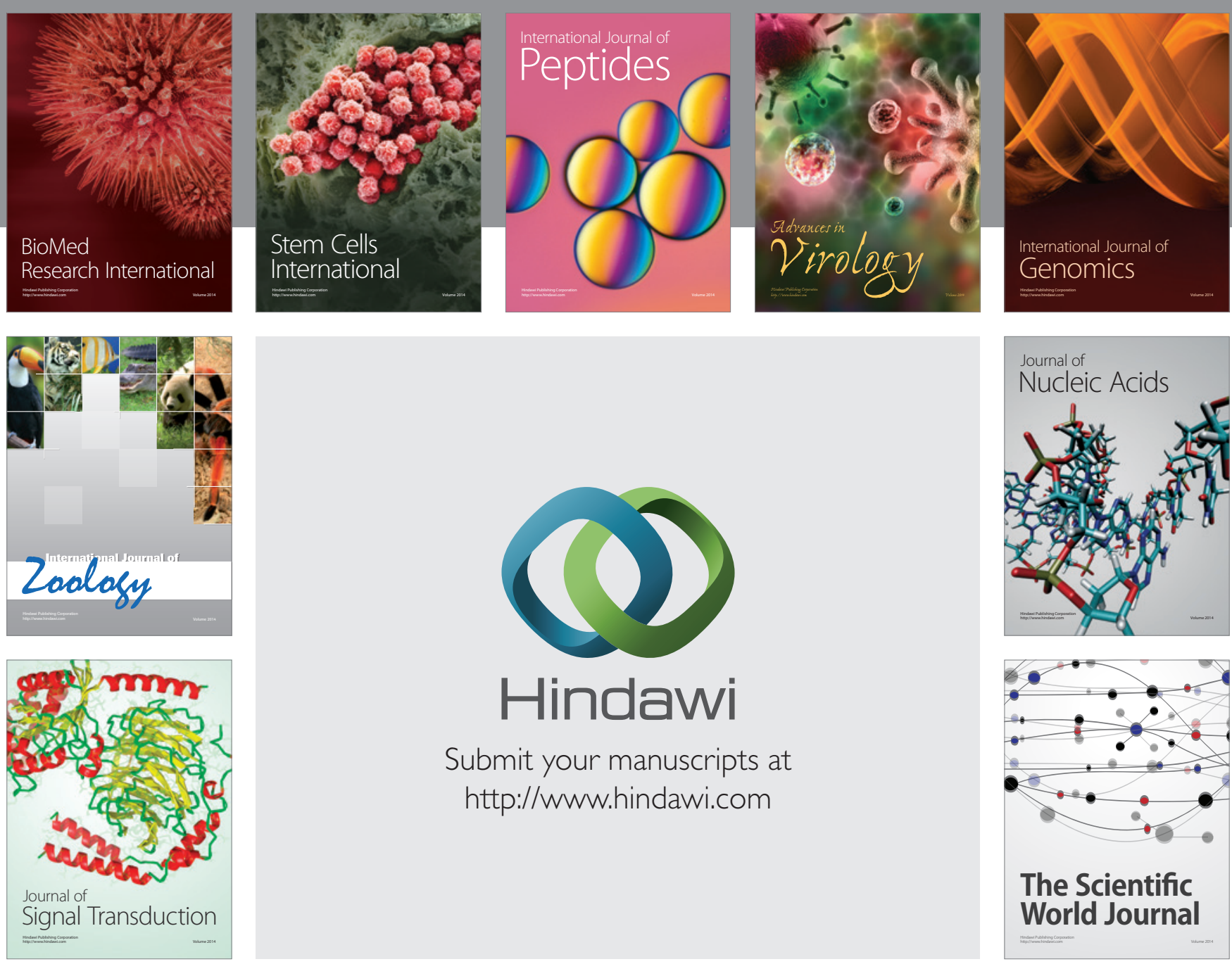

Submit your manuscripts at

http://www.hindawi.com
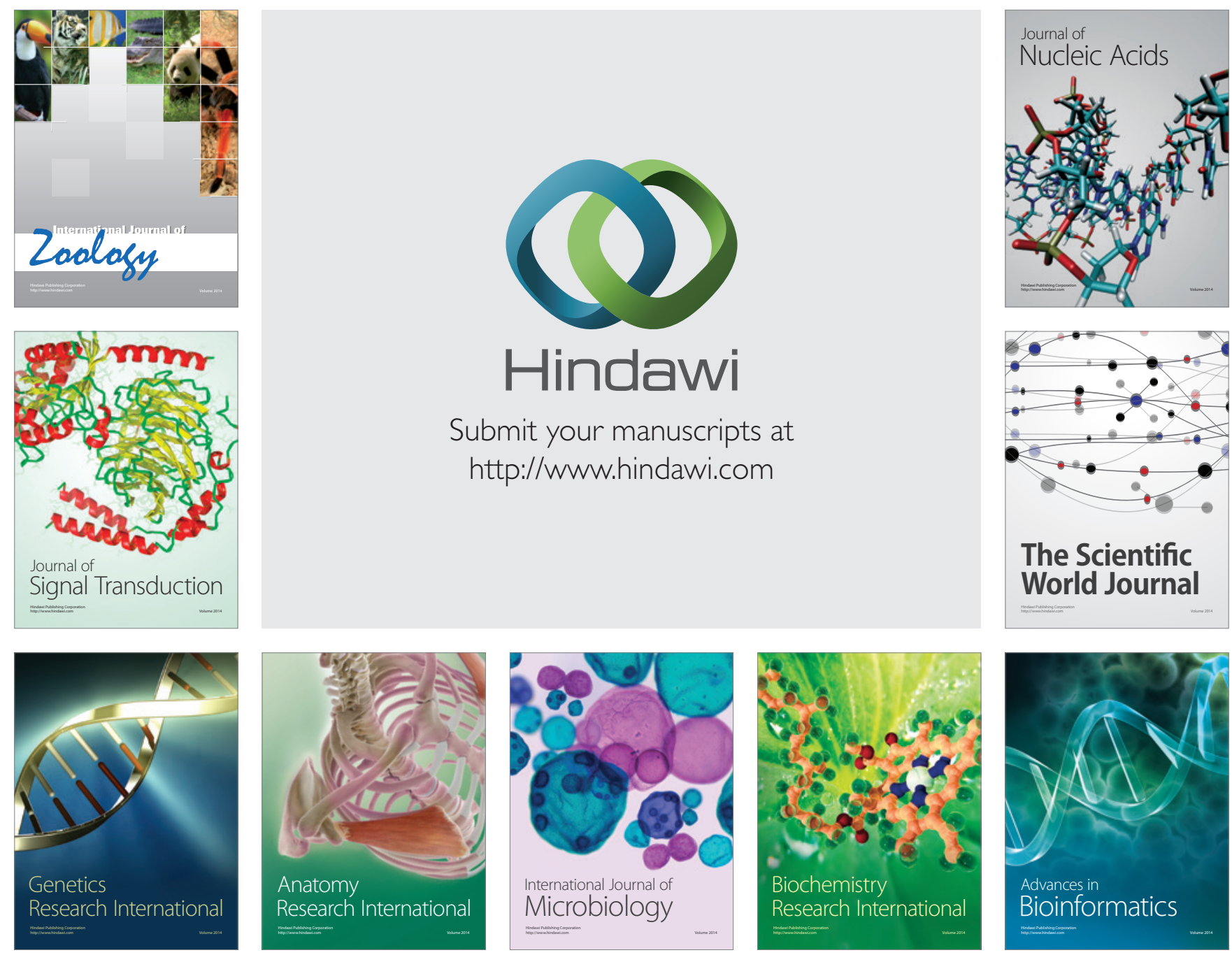

The Scientific World Journal
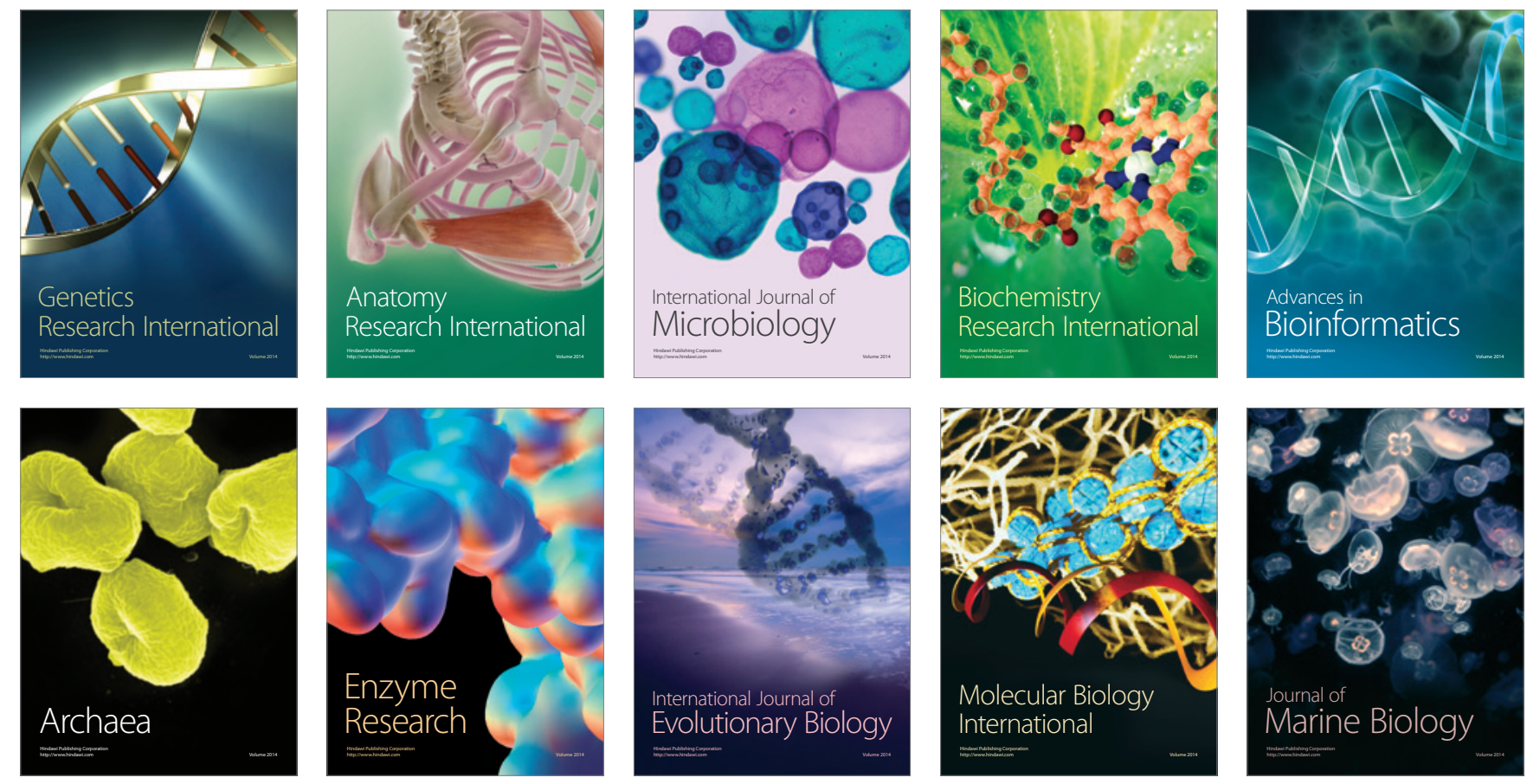